\title{
Effect of Simulation on Maternity Nursing Students' Perception, Satisfaction and Self-Confidence
}

\author{
Marwa A. A.1, Galal A. E. 2 ,Soad A. R. 3 and Hend A. E.3 \\ (1) Nursing specialist of Hosh Esacenteral hospital, Egypt. (2) Obstetrics \&gynecology, Faculty of \\ Medicine, Benha University, Egypt. (3) Obstetrics \& Women Health Nursing, Faculty of Nursing, \\ Benha University, Egypt.
}

\begin{abstract}
Aim: The current study aimed to assess the effect of simulation on maternity nursing students' perception, satisfaction and self-confidence. Setting: The study was conducted at maternity skills laboratory, Faculty of Nursing, Benha University. Design: A descriptive study was utilized. Sampling: A convenient sampleof 151 students. Tools: Three tools were used to collect data, structured interviewing questionnaire, simulation design scale, student satisfaction and self-confidence in learning. Results: $53.6 \%$ and $46.3 \%$ of the students had moderate level of perception and satisfaction regarding simulation activities, $49 \%$ of the students had high level of self-confidence in learning regarding simulation activities. There was statistically significant positive correlation between total perception, satisfaction and self-confidence score $(\mathrm{p}=0.000)$. Conclusion: Students had moderate level of perception and satisfactionin learning regarding simulation activities and had high level of self-confidence in learning regarding simulation activities. Recommendation: Students should be provided by variety of simulation-based education on maternity nursing skills to increase level of perception, satisfaction and selfconfidence.
\end{abstract}

Key words: perception, satisfaction, self- confidence, simulation

Introduction

Simulation is a student focus educational method which typically provides a new learning experience for students in a clinical setting and has been a growing part of the curricula in nursing education for the last decade. Simulations are defined as activities that mimic the real clinical environment by incorporating medical procedures, decision-making and critical thinking through techniques such as role playing and the use of devices such as interactive videos or mannequins

(Pinar et al., 2016).

The environment to perform real life simulation activities is a safe learning environment allows students to put knowledge into practice, recognize mistakes prior to entering the career field and detects areas of weakness that need improvement. Debriefing activities allow for reflection to encourage students to self-evaluate and recognize areas for improvement. Faculty encourages students and assists in improving areas of 
weakness. By participating in the activities, student's cognitive and psychomotor skills can be enhanced and students can gain a better understanding of didactic material (David, 2014).

There are three types of simulation with different abilities to mimic reality. Low fidelity simulation uses manikins that are less similar to reality, such as intravenous training arms, intramuscular injection hips. Moderate fidelity simulation uses manikins that offer breath sounds, heart sounds and bowel sounds, and allow for initiation of intravenous therapy but lack the complexity and realism of patient scenarios. High fidelity simulation is an approach to experiential learning using life size manikins with actual physiological and pharmacological responses and sophisticated interactive capability in realistic scenarios (Yuan et al., 2012).

Feedback is one of the most important aspects in simulation based learning since it promotes reflection which is a tool to promote the process of continuous learning. Therefore, debriefing sessions should be held immediately post the simulation session has been concluded to focus on the objectives that the learner did or did not achieve. The feedback given positive or negative, should allow the learners to evaluate actions and decisions. Debriefing is essential to simulation because it supports learner centered discussion and meaningful debriefing can lead to the development of clinical judgment (Mariani et al., 2013).

The use of simulation based education has been found to increase knowledge retention and build confidence and self-efficacy prior to transitioning into the practice area. Clinical simulation proves a vital role in the field of maternal- child health and allow nursing program to assess competency of student (Goldsworthy and Graham, 2013).

Simulation ensures uniformity of learning experiences, simulation puts students in situations in which need to be active and in control of learning. As a result, students develop knowledge and skills according to own needs. This stimulating environment and freedom of learning increases student motivation and interest in learning and developing confidence in abilities (Larue et al., 2015).

The use of simulation increases perception and satisfaction of learning for students in performing clinical skills. Simulation allows students to link theory to practice and develops clinical judgment, without fear of woman harm and help the preparation of students for the nursing profession and represent an effective learning method in many areas, including the acquisition of cognitive knowledge, critical thinking(Kaddoura, 2010).

Simulation is being used in undergraduate midwifery education as a way of preparing students to practice safely it has the potential to ensure graduate midwives are capable of assuming the full mantle of responsibilities and accountabilities of a midwife on graduation (Lake and Innes, 2012).

Nurse educators must explore innovative teaching methods to connect the gap between knowledge and practice in order to enhance the students' ability to function as competent nurses. Simulation has the potential to help nurse educators better train students, especially when faculty members understand issues connected with students increased preparedness for actual clinical environments. The use of simulation has the potential to help educator better 
prepare students for building nursing skill necessary for competent women care. Therefore, providing realistic situations for training nursing students in a risk free learning environment has potential for benefiting students' learning perceptions and quality of care (Chen-Yeh, 2016).

\section{Aim of the study: -}

This study aimed to assess the effect of simulation on maternity nursing students' perception, satisfaction and selfconfidence

\section{Research questions:}

1) What is maternity nursing students' perception toward simulation?

2) What is maternity nursing students' satisfaction level after their simulation training?

3) What about maternity nursing student' self-confidence after simulation training?

4) Is there a relationship between maternity nursingstudents' perception, satisfaction and selfconfidence?

\section{Subjects And Method \\ Setting of the study: -}

This study was conducted at Maternity skills laboratory, Faculty of Nursing, Benha University. sample.

Type of sample: A convenient

Sample size: -A total of 151 Maternity nursing students registered in the 3rd year at first semester in academic year 2016-2017.

\section{Tools of data collection: -}

Three tools were used for collecting data:

\section{Tool (I): - Structured} interviewing questionnaire: -

\section{It consisted of two parts:}

Part (1): -Socio demographic characteristics of the studied sample included (age, gender, marital state, place of residence).

Part (2):-Student's perception of strengths and weaknesses of simulation. It included 5items for strengths (less stressful, practice the same procedure several times, help to picture how the clinical practice in a real situation will be, help in retention of information and fun and interested), and 3items for weakness (duration was short, not really close to clinical practice and the material provided was in sufficient).

\section{Scale (SDS):-}

Tool (II):-Simulation Design

This tool comprised in 5 main categories; Objectives and information (five items), student support (four items), problem solving (five items), feedback/Guide Reflection (four items) and fidelity (two items)(Jeffries 2005).

\section{Tool (III): -Student Satisfaction and Self-Confidence in Learning:}

This tool is divided in to two parts; the first part satisfaction subscale comprised of (five items) to assess students' satisfaction in learning toward simulation activities. Part two self- 
confidence subscale comprises of (eight items) to assess students' confidence in learning(Jeffries and Rogers, 2007).

\section{A written permission}

An official permission was obtained from the Dean of the Faculty of Nursing at Benha Universityto head of department of obstetrics and women's health nursing explaining the aim of the study and time of data collection.

\section{Validity and Reliability:}

The validity of the toolssimulation design scale, student' satisfaction and self-confidence in learning was reviewed from three experts of maternal and women health nursing for content validity. The reliability of the tools was assessed by cronbach alpha test,simulation design scale $(\alpha=0.86)$ and student' satisfaction and self-confidence in learning $(\alpha=0.83)$.

\section{Ethical considerations:}

- Each student was informed about the purpose and benefit of the study at the beginning of interview and time throughout the study.

\section{Results:-}

- An oral consent was obtained from each student before starting the data collection.

- Confidentiality was ensured throughout the study process, where personal data were not disclosed, and the students were assured that all data are used only for the research purpose.

- Each student was informed that participation is voluntary and withdrawal is permissible.

\section{Statistical design:}

Data were verified prior to computerized entry. The statistical package for social science (SPSS version 20) was used for that purpose, followed by data tabulation and analysis. Descriptive statistics were applied (e.g. frequency, percentages, mean, standard deviation). Test of significance (R-test were used). A statistically significant level was considered when $\mathrm{p} \leq 0.05$, and a highly statistically significant level was considered when $\mathrm{p} \leq 0.001$. 
Effect of Simulation on Maternity Nursing Students' Perception, Satisfaction and Self-

Table (1): Distribution of the studied sample according to socio-demographic characteristics $(\mathbf{n}=\mathbf{1 5 1})$.

\begin{tabular}{|l|c|c|}
\hline \multicolumn{1}{|c|}{ Age (years) } & No. & \% \\
\hline $20-$ & 56 & 37.1 \\
$21-$ & 74 & 49.0 \\
$22-$ & 21 & 13.9 \\
\cline { 2 - 3 } Mean \pm SD & \multicolumn{2}{|c|}{$20.76 \pm 0.68$} \\
\hline Gender & 119 & 78.8 \\
\hline Female & 32 & 21.2 \\
Male & 141 & 93.4 \\
\hline Marital status & 10 & 6.6 \\
\hline Single & \multicolumn{2}{|c|}{} \\
Married & 49 & 32.5 \\
\hline Residence & 102 & 67.5 \\
\hline Urban & \multicolumn{3}{|c|}{} \\
Rural & \multicolumn{3}{|c|}{} \\
\hline
\end{tabular}

Table (2): Distribution of the studied sample according to perception level regarding simulation activities $(n=151)$

\begin{tabular}{|l|c|c|c|c|c|c|}
\hline \multirow{2}{*}{\multicolumn{1}{|c|}{ Perception items }} & \multicolumn{2}{|c|}{ High } & \multicolumn{2}{c|}{ Moderate } & \multicolumn{2}{c|}{ Low } \\
\cline { 2 - 8 } & No & $\mathbf{\%}$ & No & \% & No & \% \\
\hline Objective and information & 47 & 31.1 & 83 & 55.0 & 21 & 13.9 \\
\hline Student support & 50 & 33.1 & 63 & 41.7 & 38 & 25.2 \\
\hline Problem solving & 36 & 23.8 & 85 & 56.3 & 30 & 19.9 \\
\hline Feedback & 52 & 34.4 & 76 & 50.4 & 23 & 15.2 \\
\hline Fidelity & 68 & 45.0 & 46 & 30.5 & 37 & 24.5 \\
\hline
\end{tabular}


Moderate perception regarding objectives and information, student support, problem solving and feedback respectively. Meanwhile $45.0 \%$ of the students had high perception regarding fidelity.

Figure (1): Distribution of the students' perception regarding simulation $\operatorname{activities(n=151).}$

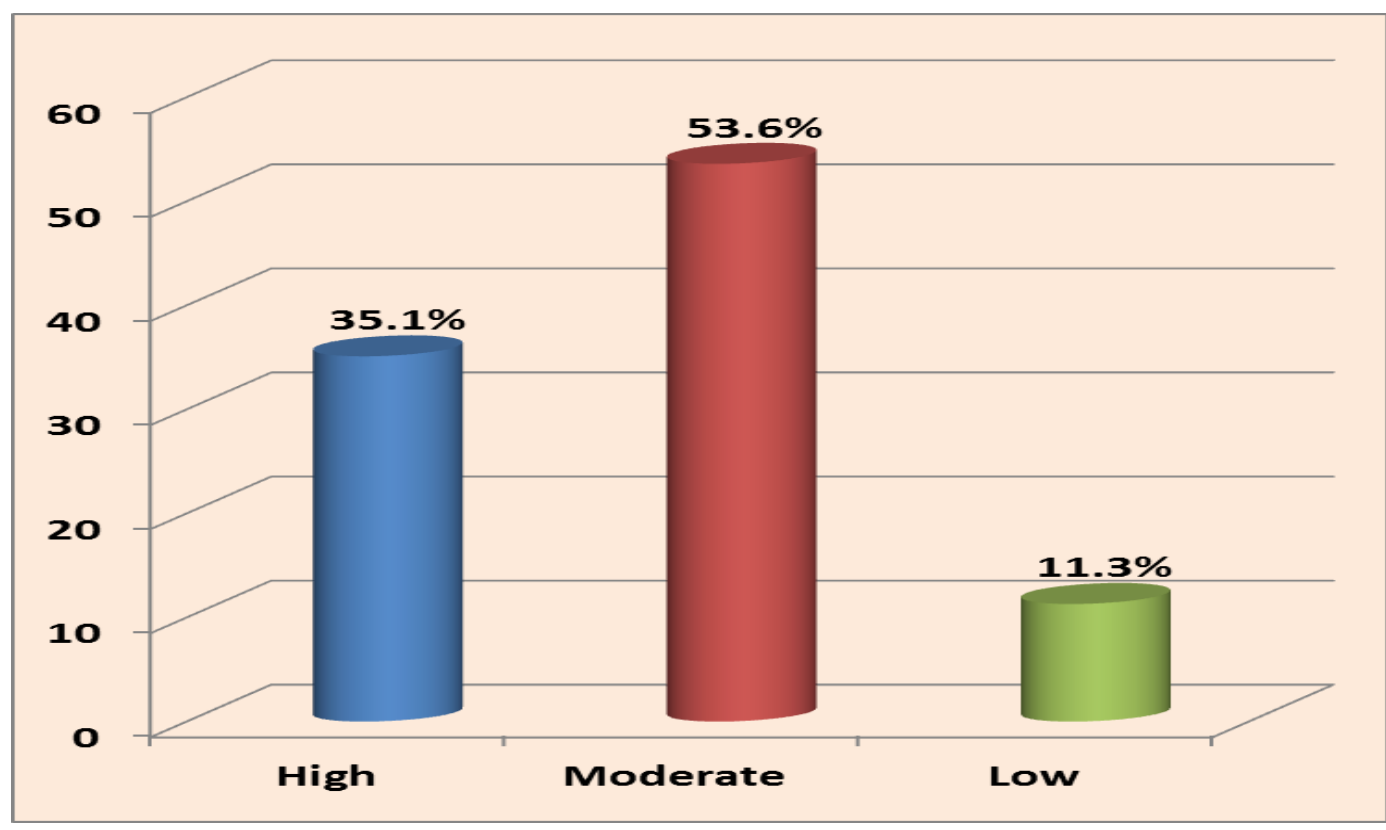

Figure (1) reveals that, $53.6 \%$ of the student had moderate level of perception regarding simulation activities. On the other hand, $11.3 \%$ had low level of perception toward simulation activities.

Table (3): Distribution of the studied sample according to satisfaction in learning towards simulation activities $(n=151)$.

\begin{tabular}{|l|c|c|c|c|c|c|}
\hline \multicolumn{1}{|c|}{ Satisfaction Items } & \multicolumn{2}{c|}{ Agree } & \multicolumn{2}{c|}{ Neutral } & \multicolumn{2}{c|}{ Disagree } \\
\cline { 2 - 8 } & No & $\%$ & No & $\%$ & No & $\%$ \\
\hline $\begin{array}{l}\text { The teaching methods used in this simulation were } \\
\text { helpful and effective }\end{array}$ & 60 & 39.7 & 75 & 49.7 & 16 & 10.6 \\
\hline $\begin{array}{l}\text { The simulation provide a variety of learning materials } \\
\text { and activities to promote learning the maternity } \\
\text { curriculum }\end{array}$ & 76 & 50.3 & 51 & 33.8 & 24 & 15.9 \\
\hline Enjoyed how instructor taught the simulation. & 72 & 47.7 & 65 & 43.0 & 14 & 9.3 \\
\hline $\begin{array}{l}\text { The teaching materials used in this simulation were } \\
\text { motivating and help to learn. }\end{array}$ & 69 & 45.7 & 61 & 40.4 & 21 & 13.9 \\
\hline $\begin{array}{l}\text { The way instructor(s) taught the simulation was } \\
\text { suitable to the learn way. }\end{array}$ & 67 & 44.4 & 64 & 42.4 & 20 & 13.2 \\
\hline
\end{tabular}


Table (3) shows that, $49.7 \%$ of the students had neutral satisfaction toward the teaching methods used in simulation were helpful and effective. While, 50.3\%, 47.7\%, $45.7 \%$ and $44.4 \%$ of the student's satisfaction agree regarding the simulation provide a variety of learning materials and activities to promote learning the maternity curriculum, enjoyed how instructor taught the simulation, the teaching materials used in this simulation were motivating and help to learn and the way instructor taught the simulation was suitable to the learn way respectively.

Figure (2): Distribution of the studied sample according to total satisfaction level in learning towards simulation activities $(n=151)$

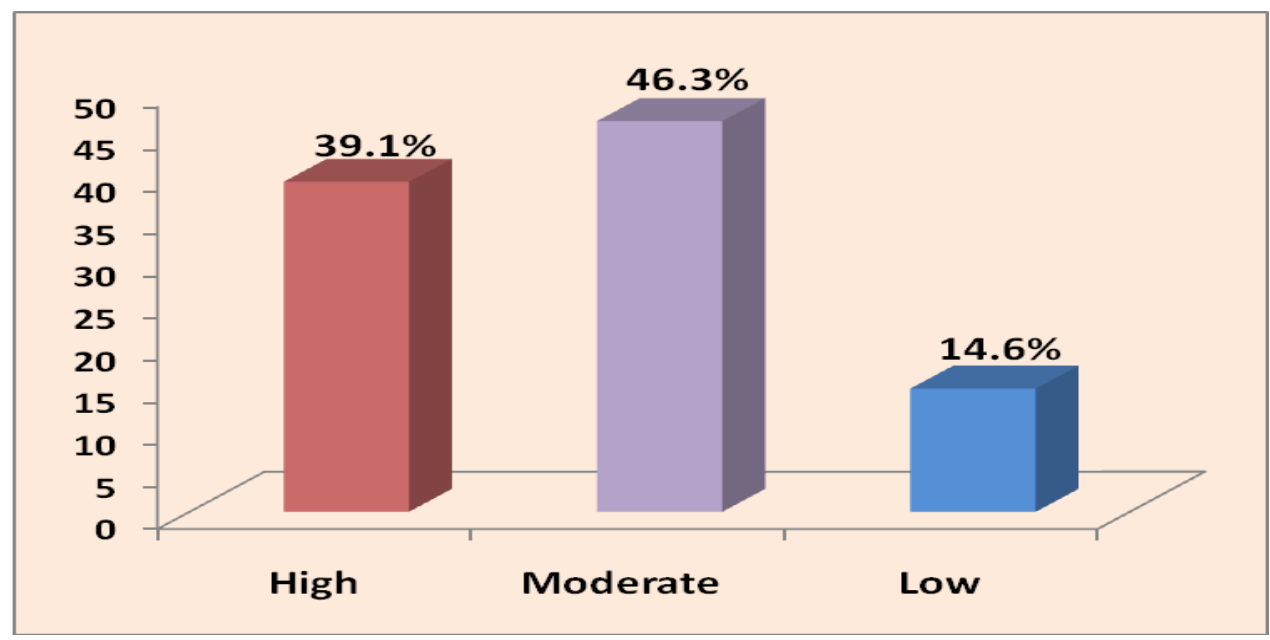

Figure (2) reveals that, $46.3 \%$ of the student had moderate satisfaction level in learning toward simulation activities. On the other hand, $14.6 \%$ of the students had low satisfaction level in learning toward simulation activities. 
Table (4): Distribution of the studied sample according to self-confidence in learning towards simulation activities $(n=151)$.

\begin{tabular}{|l|c|c|c|c|c|c|}
\hline \multicolumn{1}{|c|}{ Self-confidence items } & \multicolumn{2}{c|}{ Agree } & \multicolumn{2}{c|}{ Neutral } & \multicolumn{2}{c|}{ Disagree } \\
\cline { 2 - 8 } & No & $\%$ & No & $\%$ & No & $\%$ \\
\hline $\begin{array}{l}\text { Mastering the content of the simulation activity that } \\
\text { instructors presented to me. }\end{array}$ & 59 & 39.1 & 65 & 43.0 & 27 & 17.9 \\
\hline $\begin{array}{l}\text { Simulation covered critical content necessary for the } \\
\text { mastery of maternity curriculum. }\end{array}$ & 56 & 37.1 & 60 & 39.7 & 35 & 23.2 \\
\hline $\begin{array}{l}\text { Developing the skills and obtaining the required } \\
\text { knowledge from this simulation to perform necessary } \\
\text { tasks in a clinical setting. }\end{array}$ & 48 & 31.8 & 69 & 45.7 & 34 & 22.5 \\
\hline $\begin{array}{l}\text { Instructors used helpful resources to teach the } \\
\text { simulation. }\end{array}$ & 64 & 42.4 & 67 & 44.4 & 20 & 13.2 \\
\hline $\begin{array}{l}\text { It is responsibility as the student to learn what need to } \\
\text { know from this simulation activity. }\end{array}$ & 86 & 57.0 & 47 & 31.1 & 18 & 11.9 \\
\hline $\begin{array}{l}\text { Get help when I do not understand the concepts } \\
\text { covered in the simulation. }\end{array}$ & 57 & 37.7 & 72 & 47.7 & 22 & 14.6 \\
\hline $\begin{array}{l}\text { Use simulation activities to learn critical aspects of } \\
\text { these skills. }\end{array}$ & 63 & 41.7 & 58 & 38.4 & 30 & 19.9 \\
\hline $\begin{array}{l}\text { It is the instructor's responsibility to tell what need to } \\
\text { learn of the simulation activity content during class } \\
\text { time. }\end{array}$ & 103 & 68.2 & 31 & 20.5 & 17 & 11.3 \\
\hline
\end{tabular}

Table (4) displays that, $43.0 \%, 39.7 \%, 45.7 \%, 44.4 \%$ and $47.7 \%$ of the student had reported that neutral self-confidence toward mastering the content of the simulation activity that instructors presented to me, simulation covered critical content necessary for the mastery of maternity curriculum, developing the skills and obtaining the required knowledge from this simulation to perform necessary tasks in a clinical setting, instructors used helpful resources to teach the simulation and get help when do not understand the concepts covered in the simulation respectively. While $57.0 \%, 41.7 \%$ and $68.2 \%$ of the students had agree selfconfidence toward responsibility as the student to learn what need to know from simulation activity, use simulation activities to learn critical aspects of these skills and it is the instructor's responsibility to tell what need to learn of the simulation activity content during class time respectively. 
Figure (3): Distribution of the studied sample according total level of selfconfidence in learning towards simulation activities $(n=151)$

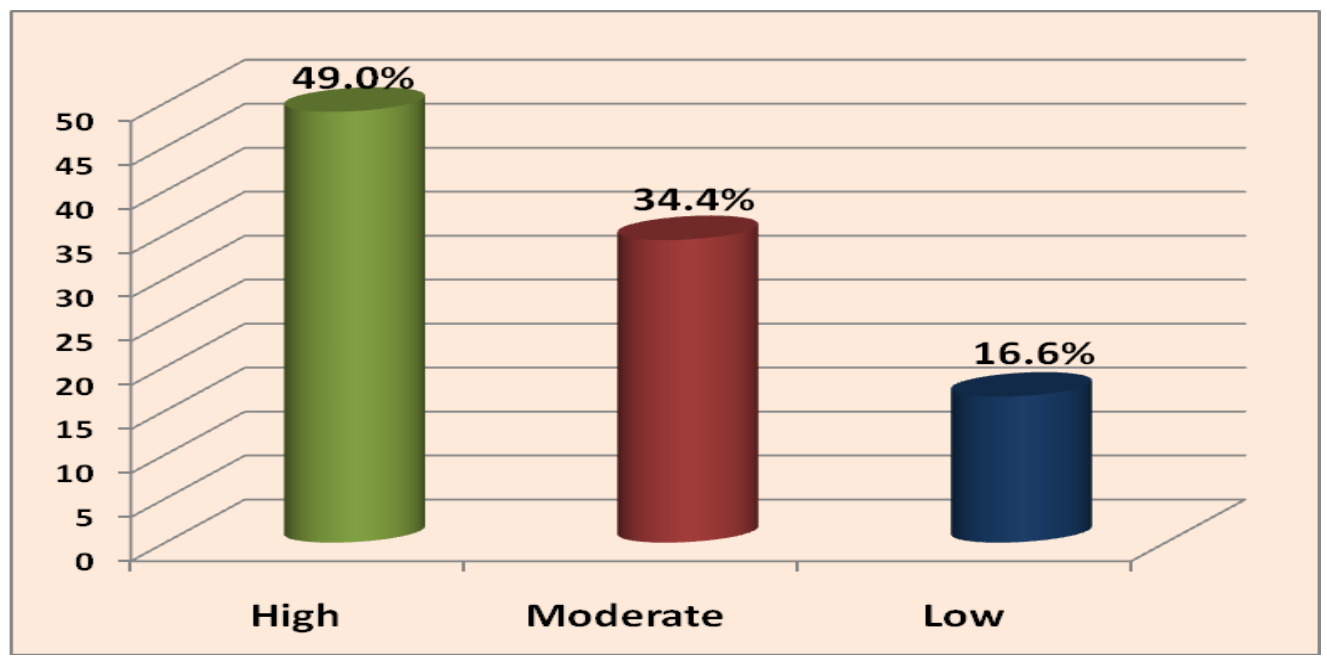

Figure (3) shows that, $49 \%$ of the students had high level of self-confidence in learning regarding simulation activities. On the other hand, $16.6 \%$ of the students had low level of self -confidence in learning regarding simulation activities.

Table (5): Correlation coefficient between total perceptions, satisfaction and selfconfidence in learning towards simulation activities scores $(n=151)$

\begin{tabular}{|l|c|c|}
\hline \multicolumn{1}{|c|}{ Variables } & \multicolumn{2}{c|}{ Total perception score } \\
\cline { 2 - 3 } & $\mathbf{R}$ & $\mathbf{P}$ \\
\hline Total satisfaction score & 0.664 & $0.000^{* *}$ \\
\hline Total self-confidence score & 0.705 & $0.000^{* *}$ \\
\hline
\end{tabular}

\section{** A highly statistical significant difference $(\mathrm{P} \leq \mathbf{0 . 0 0 1})$}

Table (12): shows statistically significant positive correlation between total perception and satisfaction scores $(\mathrm{p}=0.000)$. Moreover, there was a statistically significant positive correlation between total perception and self -confidence scores $(p=0.000)$.

\section{Discussion}

The technologies used to enable health care simulation include a wide variety of products and devices, including mannequins with varying levels of realism, computer based simulators, inert animal products, task trainers, and human cadavers. This technology is created or adapted to help address practical clinical problems when applied for training health care providers Cook et al., (2011).

Regarding characteristics of students, the finding of the present study revealed that less than half of maternity nursing students were in age ranged from $21<22$ years with mean age $20.76+0.68$ years. This finding is in accordance with Oh, (2015) who conducted a study to determine the effects of simulation based 
training on the learning outcome of nursing students and found that the mean age was 21.44 years old; more than half $65.72 \%$ of the students were aged 21 years old.

Regarding gender of the students, more than three quarters of the students were females. This finding agrees with Kelly, (2015) who conducted a study to examine the effects of simulation on nursing student knowledge, skill and attitude, reported that $96.2 \%$ of studied sample were females.

As regards marital status of the students, the finding of the present study showed that the majority of the students were single. This finding is in accordance with Dykes, (2011) who conducted a study to evaluate the effects of simulation on junior level baccalaureate nursing students' self-efficacy and intrinsic who reported that $74.6 \%$ of studied sample were singles.

Regarding perception of students toward simulation activities the findings of the present study showed that, more than half of the study sample, reported moderate level of perception regarding simulation activities. This may be due to the methods used in simulation were effective and give them clear ideas of procedure and the way of the instructors suitable to give information. This result is in accordance with Shinnick et al., (2012) who conducted a study to predict of knowledge gains using simulation in the education of prelicensure nursing students and concluded that there was a significant difference in knowledge gains with undergraduate nursing students after participation in a simulation exercise $(\mathrm{p}=$ $0.000)$

Moreover, Ardic et al., (2016) evaluated the undergraduate of nursing students' perceptions of obstetric skills following high fidelity simulation experience on 151medical and nursing student during initial clinical course. They detected increase in undergraduate student perception level and developed critical thinking skills and added that the students indicated that their total perception with the simulation applications in general $76.2 \%$, they gained knowledge $72.7 \%$, developed critical thinking $58.9 \%$, they performed clinical application close to reality $71.4 \%$, and they improved their cooperation and communication skills $60.3 \%$. According to these results, it was determined that students had positive perception about the study with simulation model.

Regarding student's satisfaction and self-confidence in learning, the results of this study showed that less than half of the students had moderate level regarding satisfaction in learning towards simulation activities and less than half of the students had high level of selfconfidence in learning regarding simulation activities. This result may be attributed to the students in the simulation session take opportunity to listening, showing and performed procedure to mannequins in a simulation lap like preparing the delivery set, positioning the woman during labour, explain the labor progress to woman, examining the placenta, care of episiotomy, preparing for immediate baby care and others.

The result of this study is congruent with several studies done by Mould et al., (2011); Hicks et al., (2009); Agha et al., (2015) to assess the effect of simulation on student satisfaction and confidence the results indicated showed a high learner satisfaction with learning by the clinical simulation and that learner's confidence in their skills. Another study was conducted to assess the level of midwife Satisfaction and self-confidence after simulation based education by Gudayu et al., (2015) who showed that, more than 
half $(54.2 \%)$ of the participants showed higher levels of satisfaction and More than half $(50.7 \%)$ of the students had increase level of self-confidence.

The result of this study is congruent with Bambini et al., (2009) who was conducted a study to evaluate simulated clinical experiences as a teaching method to increase the selfconfidence of nursing students. The findings showed a significant increase in students' confidence in performing a postpartum exam after simulation $(\mathrm{p}<$ $.01)$. The qualitative data indicated that the students' confidence was increased in relation to what to expect in the clinical setting. The study concluded that simulations increases student selfconfidence to perform clinical skills.

Regarding the correlation between students, perception, satisfaction and self-confidence, the finding of the present study demonstrates a positive statistically significant correlation between total perception, satisfaction and self -confidence score. This finding agrees with Lewis and Ciak's, (2011) study investigate the impact of simulation laboratory experiences on student satisfaction, self-confidence, and cognitive learning. Findings showed a significant gain in knowledge was found $(\mathrm{p}<.01)$. The study concluded that simulation increases knowledge and student confidence in performing skills.

\section{Conclusions}

Based on the result of the study it is concluded that; maternity nursing students had moderate level of perception and satisfaction regarding simulation activities, the students had high level of self-confidence in learning regarding simulation activities. There was statistically significant positive correlation between total perception, satisfaction and self-confidence scores. Therefore, the study questions were answered.

\section{Recommendations}

In the light of the current study findings, the following recommendation can be suggested: -

-Students should be provided by variety of simulation-based education on maternity nursing skills to increase level of perception, satisfaction and selfconfidence.

-It is necessary to train the maternity nursing student on simulation teaching strategies for clinical areas to mimic the reality of a clinical environment.

Future researches can be conducted: -Evaluate the effect of maternity nursing simulation laboratories versus other types of clinical teaching methods on student perception, satisfaction and self-confidence.

-A comparison of the effectiveness of simulation-based versus conventional training methods on maternity nursing student.

- Effect of simulation on maternity nursing students' skill related to emergency procedure with obstetrics women and its effect on increase satisfaction and self-confidence on satisfaction and self-confidence.

\section{References}

Agha, S., Alhamrani, A., and Khan, M., (2015): Satisfaction of Medical Students with Simulation based learning. Saudi medical journal. 36(6): 731-736. 
Ardic, M., Pinar, G., and Barker, E., (2016): Undergraduate nursing students' perceptions of obstetric skills following high-fidelity simulation experience. Arc journal of gynecology and obstetrics (1):19-25.

Bambini, D., Washburn, J., and Perkins, R., (2009): Outcomes of clinical simulation for novice nursing students: communication, confidence, clinical judgment. Nursing education perspectives, 30(2): 79-82.

Chen Yeh, Y., (2016): Undergraduate nursing students' perceptions of highfidelity simulation-based learning.International archives nursing health car,2: 1-5.

Cook, A., Hatala, R., Brydges, R.,Zendejas, B., Szostek, H., Wang, T., and Hamstra, J., (2011): Technology-enhanced simulation for health professions education: A systematic review and meta-analysis. Journal of theAmerican medical association. 306(9): 978-988.

David, M., (2014): Enhancing learning through simulation activities. Journal of nursing and care (3):1-6.

Dykes, M., (2011): The effects of simulation on junior level baccalaureate nursing students' selfefficacy and intrinsic motivation: doctor thesis: Georgia Southern University: 128-143.

Goldsworthy, S., and Graham, L., (2013): Simulation simplified: A practical handbook for nurse educators. Philadelphia, PA: Lippincott Williams and Wilkins.
Gudayu, T., Badi, M., and Asaye, M., (2015): Self-Efficacy, Learner Satisfaction, and Associated Factors of Simulation Based Education among Midwifery: Hindawi Publishing Corporation Education Research International 2015: 7.

Hicks, F., Coke, L., and Li, S., (2009): The effect of High-Fidelity simulation on nursing students' knowledge and performance: A pilot study. National council of state of nursing, Rush university college of nursing.

Jeffries, P.R., (2005): A framework for designing, implementing, and evaluating simulations used as teaching strategies in nursing. Nursing education perspectives. 26:96103.

Jeffries, P.R., and Rogers, K.J., (2007): Theoretical framework for simulation design. In P.R. Jeffries (Ed.), Simulation in nursing education: From conceptualization to Evaluation ( $\mathrm{pp}$. 21-33). New York, NY: National League for Nursing.

Kaddoura, A., (2010): New graduate nurses' perceptions of the effects of clinical simulation on their critical thinking, learning, and confidence. Journal continuous education nursing, 41(11):506-516.

Kelly, S., (2015): Does simulation improve nursing student knowledge, skills, and attitudes in identifying delirium superimposed on dementia? Theses and dissertations. Illinois State University: 456.

Lake, S., and Innes, J., (2012): Exploring cognitive skill development in 
midwifery education. Nurse Education in Practice, 12(5): 264-268.

Larue, C., Pepin, J., and Allard, E., (2015): Simulation in preparation or substitution for clinical placement: a systematic review of the literature. Journal of nursing education and practice, 5(9): 132-140.

Lewis, Y., and Ciak, D., (2011): The impact of a simulation lab experience for nursing students. Nursing education perspectives. 32: 256-258.

Mariani, B., Cantrell, A., Meakim, C., Prieto, P., and Dreifuerst, T., (2013):Structured debriefing and students' clinical judgment abilities in simulation. Clinical simulation in nursing, 9(5): 147-155.

Mould, J., White, H., and Gallagher, R., (2011): Evaluation of a critical care simulation series for undergraduate nursing students. Contemporary nurse. 38: $180-190$.
Oh, H., (2015): Effects of simulation based training on the learning outcome of nursing students. Advanced science and technology letters. 88: 251-255.

Pinar, G., Abay, H., and Akalin, A., (2016): The effect of simulation training on neonatal examination competency among Turkish nursing students, European scientific journal.12 (15):394-405.

Shinnick, M., Woo, M., and Evangelista, S., (2012): Predictors of knowledge gains using simulation in the education of pre licensure nursing students. Journal of professional nursing. 28(1): 41-47.

Yuan, B., Williams, B., and Fang, B., (2012): The contribution of highfidelity simulation to nursing students 'confidence and competence. International Nursing Review 59: 2633. 